\title{
VIDA AUTÉNTICA PERSONAL EN LAS DIFERENTES FORMAS SOCIALES. EL APORTE DE EDITH STEIN*
}

Bernard Schumacher**

\section{$\mathbf{P}_{\text {ara responder a las amenazas omni- }}$} presentes de la guerra y de una explosión atómica de origen terrorista, quizás existe una solución adecuada: "la transformación de la sociedad en una comunidad". ${ }^{1}$ Sólo esta conversión estaría en condiciones de fundar una paz universal y perpetua que no es posible alcanzar con las estrategias militares o diplomáticas. Esta propuesta fue proferida por el famoso escritor suizo Max Frisch con ocasión de la entrega del Premio de la Paz por la cámara alemana de libreros el 19 de septiembre de $1976 .{ }^{2}$ Él retoma una distinción propiamente alemana, y muy presente en el discurso intelectual sociológico y filosófico contemporáneo, entre dos maneras de concebir la vida común: la sociedad (Gesellschaft), por una parte, y la comunidad (Gemeinschaft), por la

* Traducción del francés por Silvia Pasternac.

** Universidad de Friburgo.

${ }^{1}$ Max Frisch, "Wir Hoffen”, en Forderungen des Tages. Porträts, Skizzen, Reden 19431982, 1983, Frankfurt am Main, editado por W. Schmitz, Suhrkamp, p. 332-42, p. 336: "durch den Umbau der Gesellschaft in eine Gemeinschaft".

${ }^{2}$ El original en alemán es "Deutscher Buchhandel". 
otra. La solución ofrecida por Max Frisch hace eco del debate de los años veinte y treinta sobre las formas sociales, que tiene su origen en la célebre obra del sociólogo alemán Ferdinand Tönnies, publicada en 1887 e intitulada Comunidad y sociedad. ${ }^{3}$

Entre los autores alemanes que tratan las relaciones fundamentales entre la sociedad y el individuo, como Theodor Litt, ${ }^{4}$ Helmuth Plessner, ${ }^{5}$ Karl Jaspers ${ }^{6}$ y Josef Pieper, el cual se opone fuertemente a la propuesta de Max Frisch, ${ }^{7}$ escogí concentrar mi atención sobre la posición adoptada por la joven filósofa alemana Edith Stein. En su largo estudio de más de ciento cincuenta páginas titulado Individuo y comunidad, ${ }^{8}$ publicado en 1922 en los famosos Beiträge zur phänomenologischen Forschung a la edad de 31 años, ella retoma la distinción mencionada más arriba y le agrega la forma social de la masa. Insiste en que el individuo se caracteriza por su pertenencia simultánea a las tres formas sociales. Por su comportamiento, tal o cual individuo puede ser percibido como perteneciente en algún punto a la masa, en otro punto a una sociedad particular (como la de los filósofos), o también a una comunidad propia. Las realidades de las formas sociales se imbrican. Edith Stein describe a la sociedad como una agrupación mecánica y racional de individuos donde el prójimo es percibido y enfrentado como un sujeto objetivado, y por lo tanto como un obje-

${ }^{3}$ Ferdinand Tönnies, Gemeinschaft und Gesellschaft. Grundbegriffe der reinen Soziologie, 1887, Leipzig, Fues; Darmstadt, Wissenschaftliche Buchgesellschaft, 1979 [Comunidad y sociedad, 1947, Buenos Aires, Losada].

${ }^{4}$ Ver Theodor Litt, Individuum und Gemeinschaft. Grundfragen der sozialen Theorie und Ethik, 1919, Leipzig, Berlín [El individuo y la comunidad. Fundamento filosófico de la cultura].

${ }^{5}$ Ver Helmuth Plessner, Grenzen der Gemeinschaft. Eine Kritik des sozialen Radikalismus, 1924, Bonn, Cohen; Frankfurt am Main, Suhrkamp, 2002 [Los limites de la comunidad. Una critica del radicalismo social].

${ }^{6}$ Ver Karl Jaspers, Die geistige Situation der Zeit, 1931, Berlín, W. de Gruyter [Ambiente espiritual de nuestro tiempo, 1933, Barcelona, Labor].

${ }^{7}$ Josef Pieper, “Grundfragen sozialer Spielregeln”, 1933 en Werke in acht Bänden, 1997, editado por Berthold Wald, vol. v, Hamburgo, Felix Meiner, p. 1-47.

${ }^{8}$ Edith Stein, "Individuum und Gemeinschaft", en Beiträge zur phänomenologischen Forschung. Jahrbuch für Philosophie und phänomenologische Forschung, 1922, p. 116-267. 
to, es decir, para retomar el término kantiano, simplemente como un medio. El sujeto conocedor permanece, además, encerrado en su mónada privada con ventanas hacia la alteridad. Desempeña un papel y una función propias de la sociedad. La comunidad es descrita como una agrupación natural y orgánica de individuos, donde el prójimo está considerado en su alteridad misma como una persona que tiene un fin en sí misma y con la que se instala una vida común. El vínculo que une a los individuos entre ellos proviene del orden de la solidaridad, la cual se puede transformar en amor auténtico.

Edith Stein concibe a la sociedad, al igual que Max Scheler y Ferdinand Tönnies, como inferior con relación a la comunidad. Sólo esta última permite, como lo veremos, el pleno florecimiento de la persona como una sustancia espiritual y como un fin en sí, libre, dotada de un sentido crítico, que vive de manera auténtica, receptiva a los valores y a la alteridad de las personas. Tal es, en mi opinión, la tesis central de Individuo y comunidad. El individuo constituye a la comunidad, la cual, a su vez, le permite al individuo realizarse doblemente. Por una parte, la comunidad alienta al individuo a manifestar lo que Edith Stein llama su 'nota personal', , su Sosein o su 'estilo propio', es decir, la manera de ser que caracteriza al individuo, el núcleo inmutable e indisoluble de ser personal que constituye a su persona en su unicidad, y que no evoluciona. Por otra parte, la comunidad incita a la plena realización de esta 'nota personal', es decir, al despliegue del Sosein, que tiene su fuente en una elección libre y responsable del sujeto actuante. La posición desarrollada por Edith Stein retoma la antigua distinción entre una forma sustancial presente desde el inicio de la existencia humana, un no ser todavía que es más que un no ser, y el actuar del ser humano, que orienta a éste de manera al mismo tiempo determinada e indeterminada, es decir, libre y responsable, hacia una meta última inscrita en el fondo de su naturaleza y que implica la libre actualización de la totalidad de su poder ser. El ser humano camina hacia la actualización -tanto por naturaleza como por el actuar

${ }^{9}$ Idem, p. 212: "die 'persönliche' Note". 
libre y por don-de las potencialidades inherentes y extrínsecas a su naturaleza, hacia un ser pleno, hacia un poseer plenamente. Podemos distinguir la plenitud de la naturaleza propia de su especie, a saber, el hecho de ser humano, de una plenitud que el ser humano alcanza por su actuar. La realización de la persona en el plano de su acto segundo va a la par con la realización de la persona comunitaria que sostiene una relación no solamente de solidaridad, sino también de amor con el prójimo.

La realización plena y entera de la comunidad, donde cada sujeto habría alcanzado su plenitud por su actuar significaría -aunque Edith Stein no lo mencione- la instauración de lo que un filósofo judío ateo y neo-comunista del siglo XX, Ernst Bloch, denomina la 'nueva Jerusalén', ${ }^{10}$ o la paz perpetua universal, para retomar la utopía de Max Frisch. Contrariamente a la esperanza atea de una trascendencia sin trascendencia de Ernst Bloch, o a la esperanza de la filosofía del progreso, que está igualmente, en mi opinión, desprovista de fundamento racional, ${ }^{11}$ Edith Stein sostiene que esa realización no es posible en el decurso histórico temporal. ¿No rechaza con esto la posibilidad de alcanzar una paz universal? ¿No queda de este modo desprovista de todo fundamento la esperanza de Max Frisch? ¿Acaso no nos vemos obligados finalmente a adoptar una actitud de desesperanza?

Me propongo examinar en el presente artículo la posición desarrollada por Edith Stein en Individuo y comunidad, que recibió poca atención por parte de los filósofos, poniéndola a dialogar con la tradición filosófica contemporánea. Analizo primero la noción de espíritu, que define una disposición a salir de sí mismo, así como la del alma llamada 'espiritual', que participa de la vida del espíritu. El alma humana está en condiciones de perderse en experiencias en la periferia de su ser, hasta el punto de quedar privada de la manifestación de su

${ }^{10}$ Ernst Bloch, Das Prinzip Hoffnung in Werkausgabe, 16 t., Frankfurt am Main, Suhrkamp, 1969, t. V [El principio Esperanza, 2004, Madrid, Trotta].

${ }^{11}$ Ver Bernard N. Schumacher, Une philosophie de l'espérance. La pensée de Josef Pieper dans le contexte du débat contemporain sur l'espérance, 2000, Paris, Cerf [Una filosofía de la esperanza, 2005, Pamplona, Eunsa Press]. 
'nota personal'. Tras haber mostrado que una existencia como ésa puede estar vinculada a las formas sociales de la masa y de la sociedad, sostengo que la forma social de la comunidad corresponde de la manera más adecuada con la autenticidad de la persona y su florecimiento. Luego desarrollo la noción de solidaridad y, más particularmente, la del amor que forma un 'nosotros' entre los sujetos. Concluyo que el despliegue completo de la 'nota personal' que permite al sujeto vivir la autenticidad de su ser se realiza cuando el individuo hace un don de sí libre y responsable a la comunidad, y al mismo tiempo salvaguarda su identidad de sujeto personal.

\section{La persona que lleva una existencia en la periferia de su ser}

Una de las tesis presentadas por Edith Stein en Individuo y comunidad es que la comunidad se puede considerar, por analogía, como una persona. Nuestra filósofa subraya, sin embargo, que la comunidad no existe ontológicamente como un puro yo. ${ }^{12}$ ¿Qué es entonces una persona? Edith Stein la define en primer lugar como un espíritu que se caracteriza por su aptitud de salir de sí mismo, es decir, de descentrarse de su cogito solipsista para abrirse al mundo que lo rodea. Se trata, por un lado, de los fenómenos corporales, de los objetos que el sujeto es capaz de experimentar por los sentidos y el conocimiento intelectual. Sin embargo, esta apertura intencional de la conciencia remite al sujeto a él mismo; dicho de otro modo, a su propio conocimiento de sí. La conciencia conoce únicamente en relación con ella misma; se abre a algo y regresa a ella misma. La relación con el prójimo en su alteridad misma se le escapa en ese retorno a sí. Por otra parte, el espíritu se abre a otras subjetividades con las cuales el sujeto funda un Mitwelt, experimenta y vive una vida social. ${ }^{13}$ Esta segunda apertura permite

${ }^{12}$ Edith Stein, "Individuum und Gemeinschaft", p. 121: "Ein Gemeinschaftssubjekt als Analogon des reinen Ich besteht nicht".

${ }^{13}$ Op. cit., p. 267. 
trascender al aislamiento del sujeto que piensa y que experimenta. Además, el espíritu se distingue tanto por la facultad intelectual como por una actitud de receptividad de los valores. ${ }^{14}$

El núcleo de la persona reside, sin embargo, según Edith Stein, en el alma llamada 'espiritual', en el sentido en que participa en la vida del espíritu, y que se puede distinguir del alma llamada 'religiosa' ${ }^{15}$ El alma escapa de toda posibilidad de auto-educación, es decir que la evolución de sus cualidades no es el resultado de un trabajo sobre sí misma, sino que es del orden de un don que proviene de otro lado. Podríamos calificar ese don como gracia sobrenatural. La filósofa alemana hace notar que

uno no se puede inculcar las cualidades del alma o desacostumbrarse a ellas. Si se tuviera que producir un cambio en esa esfera, no sería el resultado de un 'desarrollo', sino que debería ser percibido como una transformación por una fuerza del 'más allá', es decir, por una fuerza que se encontraría fuera de la persona y de todos los vínculos naturales en los cuales está implicada. ${ }^{16}$

El alma 'espiritual' se caracteriza por una actitud de receptividad con respecto a los objetos y a los sujetos en su alteridad que se expresa con el fiat $^{17}$ de un acto de libertad. Semejante comportamiento presupone, incluso si Edith Stein no lo menciona, un profundo consentimiento del valor mismo de los seres que tiene su origen último en una metafísica de la creación.

${ }^{14}$ Idem, p. 205: "Was die Person ist, das sehen wir gleichsam daran, in welcher Wertewelt sie lebt, welchen Werten sie zugänglich ist und welche Werke sie evtl. - durch Werte geleitet- schafft".

${ }^{15}$ Idem, p. 208.

${ }^{16}$ Idem, p. 210: "Die Qualitäten der Seele aber kann man sich nicht anerziehen oder abgewöhnen. Wenn in dieser Sphäre ein Wandel eintritt, so ist er nicht das Ergebnis einer 'Entwicklung', sondern als Verwandlung durch eine 'jenseitige' Macht anzusehen, das heisst eine ausserhalb der Person und aller natürlichen Zusammenhänge, in die sie verflochten ist, gelegene."

${ }^{17}$ Idem, p. 174. 
La persona puede, sin embargo, comportarse como si estuviera privada de alma 'espiritual'. En la medida en que la persona vive principalmente experiencias situadas en la periferia de su ser, el alma está de alguna manera desposeída de su 'nota personal' en el sentido en que ésta no se manifiesta, a pesar de encontrarse presente en lo más profundo del individuo. El sujeto no vive ya auténticamente lo que él es, es decir, en tanto que persona. El drama no sólo reside en el hecho de que esa alma no se dé cuenta de que su existencia en la periferia del ser está privada de la manifestación de su 'nota personal', sino también y antes que nada -y aunque Edith Stein no lo mencione- en el hecho de que semejante vida se vuelva la norma de una existencia humana realizada, es decir, dichosa. La cuestión urgente, en mi opinión, consiste en saber cómo despertar a la persona de su sueño y de su parálisis, en otros términos, cómo hacerle redescubrir su 'nota personal' a fin de que vuelva a encontrar de alguna manera su dominio sobre ella misma. Edith Stein guarda silencio. Se trata, antes que nada, de arrancarse de la rutina, 'del trabajo a casa y de casa al trabajo', para retomar una expresión de Albert Camus en una de las primeras páginas de El mito de Sísifo, o también desenraizarse de la viscosidad cotidiana admirablemente descrita por Martin Heidegger en Ser y tiempo como la dictadura del 'se' impersonal. Este despertar a las preguntas fundamentales de la existencia humana y el comienzo de una vida que concuerde con su 'nota personal', acompañado por un descentramiento de sí, se puede realizar, entre otros modos, por medio de lo que Karl Jaspers llama situaciones límite, es decir, choques existenciales. Pienso aquí en particular en la terrible experiencia de la muerte de un ser querido admirablemente descrita por Agustín en sus Confesiones, ${ }^{18}$ en la embriaguez del amor erótico, en el encuentro del verdadero amigo o también en la experiencia desestabilizadora del nacimiento de un hijo. ${ }^{19}$

${ }^{18}$ Ver San Agustín, Confesiones, 1982, México, Porrúa, trad. de Francisco Montes de Oca, libro IV, capítulo 4 (7).

${ }^{19}$ Edith Stein propone dos razones relativas al hecho de que el alma esté impregnada por la desesperación fundamental: "Choque del destino" (Schicksalschlag) y "perpetuo uso 
La satisfacción que se extrae de una vida transcurrida en la periferia (o en la superficie) del ser personal expresa antes que nada una tendencia a huir de sí mismo, y más particularmente un deseo pasajero de 'perderse a sí mismo', ${ }^{20}$ que viene acompañado con un temor de verse tal cual uno es, para retomar una expresión de Pascal; ${ }^{21}$ en opinión de Edith Stein, esto revela también una actitud de profunda desesperanza. ${ }^{22}$ Nuestra filósofa llega incluso a sostener que esa persona ya no vive verdaderamente. ${ }^{23}$ Su estado es comparable a un estado de muerte -idea que volvemos a encontrar en Gabriel Marcel- ${ }^{24}$ incluso si tiene esperanzas cotidianas en la superficie de su ser. Semejante parálisis del alma 'espiritual' conduce a la deficiencia de la persona desde el punto de vista de su receptividad a los valores y de su respuesta a la realidad. Edith Stein declara que

el mundo puede hundirse en ella [el alma], pero ella no puede ya 'encenderse' en él, ya no tiene respuestas respecto a él. La receptividad a los valores es deficiente [...] y las 'cualidades tranquilas' parecen haberse evaporado: la bondad ya no brilla en sentimientos positivos y en buenas acciones, el interior parece vaciado de todo lo que lo llenaba y de aquello con lo que se expresaba la indecible individualidad. [...] Su vida es movida por fuerzas sensibles y eventualmente por la voluntad, o transportada por fuerzas desconocidas del alma. Su vida no proviene del

excesivo de la fuerza" (ständigen übermässigen Kraftverbrauch); Edith Stein, "Individuum und Gemeinschaft", p. 212.

${ }^{20}$ Idem, p. 212: "zeitweise verloren hat".

${ }^{21}$ Ver Pascal, Pensées en CEuvres complètes, 1987, París, Gallimard, nr. 205 [139], nr. 207 [217], p. 1138-1147 [Pensamientos, 1986, Madrid, Alianza, trad. de J. Llanso].

${ }^{22}$ Edith Stein, "Individuum und Gemeinschaft", p. 211: "Es gibt sodann ein Flüchten aus den Tiefen an die Peripherie, wenn der Person ihr seelisches Leben zur Qual wird, wenn die Seele von Verzweiflung erfüllt ist. Hier ist die Seele wach, obwohl ihr Leben zugunsten des peripherischen in den Hintergrund gedrängt ist."

${ }^{23}$ Idem, p. 212: "Wenn es nicht aus der Tiefe aus seiner Seele heraus lebt, so gehen diese Kräfte seinem Leben verloren. Und nun kann es auch geschehen, dass die Seele, ohne ausgeschaltet zu werden, aufhört, leben zu spenden.”

${ }^{24}$ Ver Gabriel Marcel, Du refus à l'invocation, 1940, París, Gallimard, p. 77. 
centro de su propio ser y le falta así la originalidad y la autenticidad de una 'vida propia del núcleo'. ${ }^{25}$

Las fuerzas interiores del alma pueden ser ahogadas por el mundo exterior al que se ha abierto libremente por un fiat original. El alma 'espiritual' se retira en ella misma y se vuelve incapaz de actuar y de amar verdaderamente. ${ }^{26}$ Edith Stein describe con justeza este estado de privación de 'nota personal' como el de la no autenticidad y de la desesperanza, que puede sin embargo cohabitar con una existencia que en apariencia sería de ‘estilo propio’ al mismo tiempo que se queda en la periferia.

La desesperanza, que se puede definir como el rechazo a convertirse plenamente en lo que es la persona, se une con el contenido de un antiguo concepto un poco olvidado hoy y que los modernos llaman el aburrimiento: la acedia. El individuo impregnado de acedia parece aquejado de esquizofrenia. Se encuentra tironeado en lo más profundo de su ser entre la aspiración natural de convertirse en lo que es en tanto que persona y esta tentativa desesperada de huir de su 'nota personal' en

el ruido que ensordece del 'no hacer otra cosa más que trabajar', en el ajetreo exigente del hacedor de palabras sofistas, en la 'distracción' sin tregua en cosas encantadoras y vacías - en una palabra, en una 'no man's

${ }^{25}$ Edith Stein, "Individuum und Gemeinschaft", p. 212: "Die Welt schlägt dann wohl noch in ihr zusammen, aber sie kann nicht darin 'zünden', sie hat keine 'Antwort' mehr dafür. Die Empfänglichkeit für Werte versagt [...] und auch die 'ruhenden Qualitäten' scheinen entschwunden: die Güte strahlt nicht mehr aus in positiven Gesinnungen und gütigen Handlungen, das Innere scheint entleert von allem, was es erfüllte und worin sich die selbst unnennbare Individualität aussprach. [...] Sein Leben wird von sinnlichen Kräften und evtl. vom Willen getrieben oder auch von fremden seelischen Kräften getragen, es kommt nicht aus dem Zentrum seines eigenes Seins und es mangelt ihm daher die Ursprünglichkeit und Echtheit des 'kernhaften' Lebens."

${ }^{26}$ Idem, p. 211: "Diese Ausschaltung der Seele ist eine willkürliche. Ihr Widerspiel ist eine allen Bemühungen zum Trotz eintretende Erstarrung der Seele, ein Versiegen ihres Lebens. Das Ich steigt in seine Tiefen hinab, es verhaart darin, aber es findet eine gähnende Leere darin vor, es hat das Gefühl, als wäre ihm seine Seele abhanden gekommen, als wäre es nur noch der Schatten seiner selbst, von seinem eigensten Sein abgetrennt." 
land' que quizás estará organizada de manera muy cómoda, pero que no dejará ningún lugar para la calma de una actividad en sí plena de sentido, para la contemplación, y mucho menos todavía para la fiesta. ${ }^{27}$

La acedia impregna a la cultura contemporánea occidental, como lo confirma la presencia de los estados que ella engendra, finamente analizados por Martin Heidegger en su descripción de la vida cotidiana en Ser y tiempo. No hace alusión a los antiguos y les quita a los términos de estos estados (como los del 'se dice', de la curiosidad, de la dispersión, de la inestabilidad y de la agitación ${ }^{28}$ ) sus connotaciones religiosas o trascendentales.

La persona impregnada de acedia huye de su interior para refugiarse, por ejemplo, en la verbositas y la curiositas. Posa su mirada sobre la realidad no para captar la verdad de las cosas o para estar con ella “en una relación donde su ser está comprometido, sino, -hace notar Heidegger-, únicamente para ver". ${ }^{29}$ La mirada no cesa de revolotear de un objeto al otro. Esta multitud de ojeadas furtivas echadas sobre las cosas desemboca en una cualidad superflua de imágenes que tiende a monopolizar la existencia del sujeto. El zapping que caracteriza en nuestros días a la prensa o a la televisión sensacionalista constituye el mejor ejemplo de esta mirada superficial, de esta curiosidad hipertrófica hacia lo que el vecino dice y hace, con las cuales el ser humano descuida su ser más profundo y lo condena a ahogarse. El individuo que existe en la periferia de su ser se determina de acuerdo con lo que 'se' dice, 'se' piensa, 'se' hace. Asistimos en la persona a

${ }^{27}$ Josef Pieper, Zustimmung zur Welt. Eine Theorie des Festes en Werke, 1999, vol. VI, p. 217-85, p. 238: "in den taubmachenden Lärm des Nichts-als-Arbeitens, in die anspruchsvolle Geschäftigkeit sophistischer Wortmacherei, in die pausenlose 'Unterhaltung' durch leere Reizdinge - mit einem Wort, in ein Niemandsland, das möglicherweise recht komfortabel eingerichtet ist, aber keinesfalls Raum lässt für die Ruhe eines in sich selbst sinnvollen Tuns, für die Kontemplation und erst recht nicht für das Fest."

${ }^{28}$ Ver Martin Heidegger, Sein und Zeit, $1986^{16}$, Tübingen, Max Niemeyer, p. 167-73 [Ser y Tiempo, 1997, Santiago, Editorial Universitaria].

${ }^{29}$ Idem, p. 172: "nicht um das Gesehene zu verstehen, das heisst in ein Sein zu ihm zu kommen, sondern nur um zu sehen". 
un desafecto de su 'nota personal' y a una destrucción progresiva de la dimensión llamada 'espiritual' del alma. Ésta se mueve en el seno de la dictadura del 'se' que no es Persona, y que dispensa al individuo de vivir auténticamente para él mismo y para su poder ser. El 'Se'le evita ser en el sentido pleno del término. Si el individuo desea vivir en la autenticidad, es decir, ser plenamente sí mismo, necesitará realizar una ruptura con el 'Se'. El acto de resistencia hacia la dictadura del 'Se' le permite al sujeto tomar conciencia de su dimensión plenamente personal, a saber, que no es solamente un ejemplar de la especie humana en general como lo preconizan la masa y la sociedad.

\section{El tipo de individuo en la masa y en la sociedad}

\subsection{El individuo de la masa}

El individuo de masa no está considerado en su calidad de objeto -lo cual es el caso en la sociedad- ni de apertura a la alteridad viviente -como es el caso en la comunidad-, sino más bien de acuerdo con sus acciones uniformes desprovistas de toda 'nota personal' ${ }^{30} \mathrm{El}$ tipo de individuo constitutivo de la masa vive en la periferia de su ser personal y se encuentra sometido a un determinismo emocional y corporal. No actúa, es decir que no plantea acciones libres. Reacciona siguiendo el modelo causal determinista. En la masa, cada individuo adopta un comportamiento idéntico, ${ }^{31}$ que puede serle sugerido de manera extrínseca. Su acción -o más precisamente su reacción- tiene como fundamento su afectividad, que está en el origen de sus convicciones infundadas,

${ }^{30}$ Edith Stein, "Individuum und Gemeinschaft", p. 241-2: "weil das psychische Individuum nicht 'aus seiner Seele heraus lebt'. Wo das nicht der Fall ist, da trägt der ganze Charakter keine persönliche Note, wir haben (für den äusseren Anschein wenigstens) keine Individualität im Sinne qualitativer Einzigartigkeit, sondern nur das Exemplar eines Typus."

${ }^{31}$ Idem, p. 218-9: "Die Masse ist ein Zusammen sich gleichförmig verhaltender Individuen. Es fehlt an einer inneren Einheit, aus der heraus das Ganze lebte." "Die Einheitlichkeit im Verhalten der Masse, die ihr den Charakter einer 'Kollektiv-Gegenständlichkeit' verleiht, ist begründet in der 'Reizbarkeit' der individuellen Psyche durch fremdes psychisches Leben und ihrem Reagieren mit gleichem Verhalten." 
de sus opiniones, que no tienen prácticamente un tenor. El hecho de que representaciones caracterizadas por su poderoso destello sensual y su importante capacidad para producir cierto comportamiento se fijen en el individuo muestra, según Edith Stein, que han sido aceptadas sin pensamiento lógico ni crítico. ${ }^{32} \mathrm{El}$ individuo de masa está así desprovisto de libertad real y de pensamiento crítico. Es terreno fértil para las emociones y las ideas preconcebidas desprovistas de todo fundamento racional, es decir, para la formación de un totalitarismo, como lo percibió admirablemente Hannah Arendt. ${ }^{33}$

Además, el individuo de masa vive en el anonimato, cerrado sobre sí mismo; desaparece 'en su propia experiencia'. ${ }^{34}$ Aunque asume un comportamiento idéntico sobre un punto particular, la totalidad de su existencia no se deja reducir, sin embargo, a la dimensión de la masa. Tal individuo particular puede en efecto reaccionar, en algún sentido, como un individuo de la masa (el maestro sindicalizado que sale a las calles para reivindicar mejores condiciones de trabajo), y en otro sentido como un individuo de una sociedad particular (el maestro en su función y su papel de maestro), o de una comunidad específica (el maestro como persona que tiene una relación de solidaridad y de amor con el prójimo). Así, un individuo puede estar desprovisto de pensamiento crítico desde cierto punto de vista y ejercerlo desde el otro. Esto significa que puede vivir de una manera tanto no auténtica como auténtica. Edith Stein hace notar que la vida cotidiana de cada individuo participa de la estructura social de la masa que vive de manera no auténtica y que ignora la dimensión de la vida personal y el pensamiento crítico. En efecto, aceptamos con regularidad, sin reflexión lógica, cierto número de ideas apoyándonos sobre la confianza otorgada al prójimo que -lo suponemos a priori-ha razonado de manera crítica. ${ }^{35}$

${ }^{32}$ Idem, p. 220.

${ }^{33}$ Ver Hannah Arendt, Considérations morales, 1996, Paris, Rivage poche/Petite Bibliothèque, p. 47-56.

${ }^{34}$ Edith Stein, "Individuum und Gemeinschaft", p. 263: "ein Aufgehen im eigenen Erleben".

${ }^{35}$ Ver Edith Stein, "Individuum und Gemeinschaft", p. 222. 
Yo sostengo, por mi parte, que somos, por nuestra naturaleza humana -¿quizás por eso Edith Stein sostiene la imposibilidad de alcanzar una comunidad perfecta?- seres esencialmente tironeados desde el interior entre el llamado de la comunidad (un llamado a su realización plena) y el de la masa y de la sociedad. La viscosidad cotidiana no cesa de pegarse al individuo: él no puede extraerse de ella por sí mismo.

\subsection{El individuo de la sociedad}

Si nos colocamos ahora en el plano de la sociedad, que en muchos aspectos funciona y se desarrolla como una máquina, constatamos que el individuo una vez más no se caracteriza por la realización de su 'nota personal', sino principalmente por su papel y su función en el interior del todo, como por ejemplo el tipo de individuo llamado 'maestro'. Sometido al principio de la búsqueda del máximo de productividad, de rentabilidad y de eficacia, el individuo es reemplazable. Edith Stein precisa que

la vida de la sociedad reside en la actividad de sus miembros exigida por la realización de su meta, con respecto a la cual no tiene ninguna importancia que sean justamente esos individuos los que realicen el trabajo en cuestión. Cada individuo, por principio, es reemplazable. ${ }^{36}$

Desde esta perspectiva, el individuo equivale a un objeto utilizable como un simple medio con miras a un fin. Puedo, por ejemplo, considerar a mi colega de trabajo en su papel y en su función de maestro, es decir, de individuo reemplazable por cualquier otro sujeto que pueda cumplir el mismo papel y la misma función. Mirar a ese colega como un fin en sí depende de hecho de la forma social de la comunidad. Edith Stein indica, sobre el individuo de la sociedad,

${ }^{36}$ Idem, p. 230: "Das Leben der Gesellschaft besteht in der durch ihre Zwecke geforderten Tätigkeit ihrer Glieder, wobei es unwesentlich ist, dass gerade diese Individuen die betreffende Arbeit verrichten und jedes prinzipiell durch andere ersetzbar." 
que cada uno se concebiría y concebiría al prójimo como un instrumento para alcanzar la meta que le sirve a la sociedad entera. Cada uno se colocaría o sería colocado de manera sistemática en el lugar (es decir que se encargaría de las funciones de la sociedad) donde, con sus capacidades reconocidas, podría contribuir mejor a la realización de la meta. ${ }^{37}$

Una forma social que se basara únicamente sobre la masa y sobre la sociedad, y donde la dimensión personal y comunitaria faltaran sería, ciertamente, un mecanismo construido de manera absolutamente brillante y perfecta, pero no funcionaría. ${ }^{38}$ En efecto, toda sociedad presupone necesariamente la existencia mínima de una comunidad. Edith Stein subraya en repetidas ocasiones en Individuo y comunidad que una "pura sociedad que no fuera también hasta cierto grado una comunidad no podría subsistir". ¿Cuáles son las razones que ella exhibe para apoyar esta afirmación?

Habíamos visto que los individuos de una sociedad particular se conciben recíprocamente como objetos que cumplen un papel y una función particulares con vistas a alcanzar un fin particular. La concepción y la elección de ese fin tienen su origen en una comunidad de personas que son capaces de otorgarle un sentido y una motivación a las acciones. Además, para considerar al prójimo como un objeto, necesariamente se lo tiene que haber captado previamente, como lo subrayará Jean-Paul Sartre en El ser y la nada, como un sujeto libre, y haberse situado con el prójimo en el plano ingenuo de un encuentro intersubjetivo.

${ }^{37}$ Idem, p. 232: "Jeder würde hier sich und den anderen als Werkzeug zur Erreichung des Zweckes ansehen, dem die ganze Gesellschaft dient, und jeder würde sich planmässig an den Platz stellen oder dahin gestellt werden (d.h. diejenige gesellschaftliche Funktion übernehmen), wo er seinen erkannten Fähigkeiten nach am besten zur Erreichung des Ziels beitragen kann." "Man lebt nicht naiv, sondern sieht sich mit den Augen der anderen und stimmt sein Verhalten darauf ab, dass das Bild der eigenen Person sich harmonisch in den Rahmen des Ganzen einfügt", p. 263.

${ }^{38}$ Idem, p. 234: "Eine Gesellschaft, die nichts als Gesellschaft wäre, das wäre ein -evtl. Tadellose konstruierter- Mechanismus, der nicht funktionieren könnte."

${ }^{39}$ Idem, p. 232: "Dass eine reine Gesellschaft, die nicht bis zu einem gewissen Grade auch Gemeinschaft ist, nicht bestehen kann". "Gemeinschaft ohne Gesellschaft ist also möglich, Gesellschaft ohne Gemeinschaft dagegen nicht”, p. 118. 


\section{Edith Stein precisa que}

no se pueden conocer los medios de provocar una impresión sobre la masa sin un buen conocimiento de su vida interior tal como puede ser obtenida únicamente por una entrega ingenua. Lo que distingue al observador de quien vive ingenuamente con [su prójimo] es que éste aprovecha racionalmente lo que le ofrece la vida en comunidad. Pasa de una experiencia ingenua a una actitud de conocimiento. Hace de la interioridad desconocida un objeto, en lugar de 'reaccionar' directamente respecto a él. Recupera el conocimiento para los fines de su acción. ${ }^{40}$

Vemos cómo se dibuja aquí un primer elemento de la definición de la comunidad presentada por Edith Stein: el reconocimiento del prójimo en su alteridad radical que emerge a partir de un primer encuentro ingenuo. Gabriel Marcel hablará a su vez de intersubjetividad, corazón de su filosofía personalista. En un hermoso fragmento de Ser y tener, publicado en 1935, el filósofo francés declara:

El otro en tanto que otro existe para mí sólo en tanto que yo estoy abierto a él (que es un tú), pero sólo estoy abierto a él en tanto que yo ceso de formar conmigo mismo una especie de círculo en el interior del cual alojaré de algún modo al otro, o más bien su idea; pues, con relación a ese círculo, el otro se convierte en la idea del otro -y la idea del otro no es ya el otro en tanto que otro, es el otro en tanto que relacionado conmigo. ${ }^{41}$

${ }^{40}$ Idem, p. 118: "Man kann die Mittel nicht kennen, mit denen auf die Menge Eindruck zu machen ist, ohne eine Vertrautheit mit ihrem Innenleben, wie sie nur in naiver Hingabe zu gewinnen ist. Was den Beobachter vom naiv Mitlebenden unterscheidet, ist dies, dass er das, was ihm das Gemeinschaftsleben bietet, rationell ausnützt; dass er aus dem naiven Erleben in die erkennende Haltung übergeht, die fremde Innerlichkeit zum Gegenstande macht, anstatt unmittelbar darauf zu 'reagieren', und die Erkenntnis für die Zwecke seines Handelns verwertet." "Man muss den anderen zunächst einmal als Subjekt genommen haben, um seine Subjektivität zum Objekt machen zu können", p. 232; "in denen eine Person die andere wahrnimmt, sie bewertet usw., ist der Übergang zur 'gesellschaftlichen' Einstellung möglich, in der das andere Subjekt als ein Objekt von besonderer Eigenart betrachtet wird", p. 240.

${ }^{41}$ Gabriel Marcel, Être et Avoir, 1935, París, Aubier, p. 155: "L'autre en tant qu'autre n'existe pour moi qu'en tant que je suis ouvert à lui (qu'il est un toi), mais je ne suis ouvert à lui que pour autant que je cesse de former avec moi-même une sorte de cercle à l'intérieur duquel je logerais en quelque sorte l'autre, ou plutôt son idée ; car par rapport à ce cercle 
La aceptación ingenua y primaria del prójimo presupone una actitud de receptividad y de descentramiento de sí mismo, de trascendencia del cogito propio. La apertura y el consentimiento de la alteridad -que Edith Stein describe como “cierta 'actitud' de las personas entre ellas"- ${ }^{42}$ es una parte constitutiva de la naturaleza del ser personal; dicho de otro modo, a partir del momento en que hay un sujeto humano, hay ya necesariamente comunidad. La intersubjetividad expresa una apertura de acogida recíproca. Una de las razones de esta presencia comunitaria reside, en mi opinión, en el hecho de que todo ser humano es proyectado desde su concepción en el seno de una estructura de relaciones comunitarias que lo impregnan profundamente y que se expresan por el lenguaje, la cultura y la tradición, con lo que fundan un flujo de experiencias colectivas. El problema esencial consiste en conocer el tenor de esta relación: puede revestir un contenido positivo, como en Gabriel Marcel o Robert Nozick, o negativo, como en Jean-Paul Sartre.

\section{La comunidad y la persona}

Edith Stein concibe a la comunidad humana como un organismo vivo que crece y que muere, compuesto por sujetos autónomos, dotados de motivaciones propias, y que pueden responder a unos valores. $\mathrm{La}$ relación entre sujetos no es del orden de un 'yo-él-objeto', donde el prójimo es percibido en su alteridad como un objeto, y por lo tanto como un sujeto objetivado, sino de un 'yo-tú' donde el sujeto está fundamentalmente abierto al prójimo reconocido como un fin en sí. La esfera del yo se amplía a un intercambio de experiencias y de valores, y desarrolla el carácter personal por el ejercicio de la voluntad

l'autre devient l'idée de l'autre - et l'idée de l'autre ce n'est plus l'autre en tant qu'autre, c'est l'autre en tant que rapporté à moi." [Ser y tener, 1996, Madrid, Capparrós Editores, trad. de Ana María Sánchez López].

${ }^{42}$ Edith Stein, "Individuum und Gemeinschaft”, p. 242: “eine gewisse 'Einstellung' der Personen aufeinander". 
sobre unas disposiciones psíquicas, por la práctica de buenas o de malas costumbres. Edith Stein describe esa comunidad como 'personalidades autónomas', o 'realidades espirituales autónomas" ${ }^{43}$ que se expresan por la constitución de lo que podríamos llamar un 'nosotros'. Además de esta apertura al mundo y al prójimo, propia del espíritu, la comunidad requiere de una unidad cualitativa de los individuos que la componen, y cuya meta reside en ella misma. Sin esta unidad fundamental interior, los individuos vivirían en apariencia de comunidad, y cada uno perseguiría su propio objetivo. Edith Stein anota que

la sociedad exige de sus 'elementos' únicamente que ocupen una función que contribuya a la realización de su meta constitutiva. No profiere ninguna pretensión sobre la totalidad de su ser interior. Ocurre algo diferente en la verdadera comunidad. Existe, en la comunidad y los individuos que la componen, una aspiración viviente a superarse y alcanzar una unión plena. ${ }^{44}$

La solidaridad caracteriza el vínculo entre los sujetos de una comunidad, el cual ha sido admirablemente descrito por Gabriel Marcel a partir del encuentro con un desconocido. ${ }^{45}$ La solidaridad permite, según Edith Stein, considerar a la comunidad de manera analógica como una persona. No constituye sin embargo todavía su realización en cuanto a su acto segundo. Para que así sea, necesita superar el plano de la solidaridad y de la buena voluntad hacia el prójimo para alcanzar el del amor que se expresa por la comunión. Coloca el principio amor expresado por un 'nosotros' en el centro de la realización de la comunidad, que implica la de los individuos que participan en ella.

${ }^{43}$ Idem, p. 249: “selbständige Persönlichkeiten” y "selbständige geistige Realitäten”. Ver p. 177, 185, 193, 197.

${ }^{44}$ Idem, p. 258: "Die Gesellschaft verlangt von ihren Elementen nur, dass sie eine Funktion übernehmen, die zur Erreichung des ihr konstitutiven Zweckes beiträgt - sie erhebt keinen Anspruch auf ihr ganzes inneres Sein. Anders liegt die Sache bei der echten Gemeinschaft. In ihr bzw. in den Individuen, die ihr angehören, lebt ein Streben, über sich selbst hinaus und zu einer vollkommenen Vereinigung zu gelangen."

${ }^{45}$ Ver Gabriel Marcel, Le mystère de l'Être, 1951, París, Aubier, t. I, p. 195 s. [El misterio del ser, 1971, Buenos Aires, Sudamericana, trad. de María Eugenia Valentie]. 
El amor se funda en una ontología de la intersubjetividad positiva donde la individualidad de los participantes en presencia no desaparece en una unidad fusional, sino que establece una unión fundamental expresada por el 'nosotros'. No se trata, sin embargo, como no cesa de subrayarlo Edith Stein, de una nueva entidad ontológica que vendría a suplantar a la individualidad propia de los participantes. "Amar, subraya el célebre filósofo político Robert Nozick, es querer formar un nosotros con un ser en particular." 46 El bienestar de uno de los participantes depende del bienestar del otro. Este último es percibido como una ayuda -y no como un peligro, un objeto o una función-indispensable para la realización del individuo y de la comunidad. El 'yo' no desaparece en el 'nosotros', sino que su identidad está preservada en él y es estimulada en su crecimiento individual. La nueva identidad del 'nosotros' se suma a la identidad personal.

Formar parte de un nosotros confiere una nueva identidad, una identidad suplementaria. Esto no significa que uno no tiene ya identidad propia o que uno ya no existe más que en función del nosotros. Sin embargo, la identidad de uno es modificada. ${ }^{47}$

El 'nosotros' no es autoritario. No consume al 'yo', sino que le deja su plena autonomía y lo rodea con un profundo respeto. Además, la presencia del 'nosotros' no amenaza de ningún modo con aniquilar la libertad de los sujetos presentes. El filósofo estadounidense explica que

cada elemento de un nosotros quiere poseer al otro completamente; sin embargo, cada uno tiene también necesidad de que el otro conserve su independencia y no esté a su servicio. Sólo una persona autónoma

${ }^{46}$ Robert Nozick, Examined Life. Philosophical Meditations, New York, Simon and Schuster, 1989, p. 70: "love is wanting to form a we with that particular person" [Meditaciones sobre la vida, 2002, Barcelona, Gedisa, trad. de Carlos Gardini].

${ }^{47}$ Robert Nozick, Examined Life, p. 71: "To be part of a we involves having a new identity, an additional one. This does not mean that you no longer have any individual identity or that your sole identity is as part of the we. However, the individual identity you did have will become altered." 
podría constituir un compañero apropiado en una identidad común que engrandezca y enriquezca la propia identidad individual. Por supuesto que el bienestar -cosa que nos importa-requiere también de esa autonomía. Esto coexiste sin embargo con el deseo de poseer enteramente al otro. Según yo, ese deseo no proviene forzosamente de una voluntad de dominación. Lo que uno quiere, lo que uno necesita, es poseer al otro tan completamente como uno se posee a sí mismo. Es una expresión del hecho de que uno está formando una nueva identidad común con el otro. O quizás ese deseo es simplemente el de formar una identidad con el otro [...] en un nosotros amoroso, la autonomía del otro y la posesión total se reúnen en la formación de una identidad ampliada, común a ambos. ${ }^{48}$

\section{Los dos 'yo' que forman un 'nosotros' se caracterizan por una inte-} racción creciente que sin embargo no desemboca nunca en una identificación completa. El prójimo sigue siendo un misterio en la relación de amor, alguien cercano que escapa de nuestra entera posesión. Louis Lavelle captó muy bien, en su obra Conduite à l'égard d'autrui, esta distancia del prójimo, siempre presente en lo referente al amor:

Hay entonces entre usted y yo una barrera impermeable que yo puedo hacer retroceder más y más, pero que nunca puedo abolir. Protege el secreto de cada uno que hace de él una iniciativa pura, el primer comienzo de él mismo, un ser que no cesa de engendrarse cada vez de nuevo, un sí mismo tan misterioso para mí, en el pasado que trae tras él, como es misterioso para sí mismo en el provenir que se abre frente a él. Este intervalo que lo separa de mí funda su independencia y, por consi-

${ }^{48} \mathrm{Op}$. cit., p. 74: "Each person in a romantic we wants to possess the other completely; yet each also needs the other to be an independent and nonsubservient person. Only someone who continues to possess a nonsubservient autonomy can be an apt partner in a joint identity that enlarges and enhances your individual one. And, of course, the other's well-being-something you care about- requires that non-subservient autonomy too. Yet at the same time there is the desire to possess the other completely. This does not have to stem from a desire to dominate the other person, I think. What you need and want is to possess the other as completely as you do your own identity. This is an expression of the fact that you are forming a new joint identity with him or her. Or, perhaps, this desire just is the desire to form an identity with the other $[\ldots]$ in a romantic we the autonomy of the other and complete possession too are reconciled in the formation of a joint and wondrous enlarged identity for both." 
guiente, su existencia misma. Y no puedo soportar a veces ser incapaz de cruzarla. Pero no es amar al prójimo no amarlo en esa independencia misma que lo separa de mí. ${ }^{49}$

El principio amor se caracteriza por el fracaso de la pareja en mudar en una unidad, a pesar del profundo deseo del 'yo'. Existe una distancia ontológica infranqueable que hace que el amado permanezca resueltamente exterior al amante. El amor no consigue llenar la distancia entre el amado y el amante. No cesa al contrario de confirmar esta distancia ontológica, aunque haga entrar al prójimo en la intimidad misma del sujeto, intentando con ello romper la soledad ontológica de la persona humana, que es experimentada frente a su propia muerte. El principio amor expresa una actitud de apertura y de abandono donde el prójimo seguirá siendo el prójimo en el sentido en que representa un misterio fundamental, puesto que es al mismo tiempo una presencia y una ausencia. El amor únicamente puede existir y florecer en la aceptación de la diferencia ontológica del otro por la cual éste último no sólo es concebido, sino también querido como otro que no es uno. A partir de que el amante afirma conocer al amado, lo reduce a una cosa, de la cual domina todas las dimensiones de su ser; se vuelve, para retomar una expresión de René Descartes, 'amo y poseedor' del amado. Se sitúa así en el nivel de la masa y de la sociedad. El verdadero amante no desea que el amado exista con relación a él (el amante), sino en sí, por sí mismo (el amado). El principio amor atorga al prójimo tanto el hecho de ser en el ser, a saber, en su existencia, como el hecho de ser lo que es, a saber, en su esencia y desarrollar lo que es. La libertad del

${ }^{49}$ Louis Lavelle, Conduite à l'égard d'autrui, París, Albin Michel, 1957, p. 70: “il y a donc entre vous et moi une barrière imperméable que je puis reculer toujours, mais que je ne puis jamais abolir. Elle protège le secret de chacun qui fait de lui une initiative pure, le premier commencement de lui-même, un être qui ne cesse de s'engendrer toujours à nouveau, un soi aussi mystérieux pour moi dans le passé qu'il porte derrière lui qu'il est mystérieux pour lui-même dans l'avenir qui s'ouvre devant lui. Cet intervalle qui le sépare de moi fonde son indépendance et par conséquent son existence même. Et je ne puis souffrir parfois d'être incapable de le franchir. Mais ce n'est pas aimer autrui que de ne pas l'aimer dans cette indépendance même qui le sépare de moi." 
amante no es de ninguna manera la puesta en peligro de la libertad del amado, sino que consigue unirse gracias al principio de amor a una libertad diferente sin por ello ser reducida a una cosa.

La base de la forma social de la comunidad reside, para Edith Stein, no solamente en la apertura ingenua a la alteridad caracterizada por la solidaridad o la buena voluntad, en esta trascendencia del encierro de la mónada sobre sí misma, en el descentramiento fundamental del yo, sino también en el acto de libertad que le permite al individuo actuar en el plano de su ser personal. Como no está sometido de manera determinada a las presiones exteriores o a las influencias de la masa, el individuo se vuelve responsable de su reacción hacia ellos. Es responsable de una vida que se definiría por la autenticidad y el apego a su ser personal, o por la falta de autenticidad de una existencia en la periferia de su ser, sometida a la dictadura del 'Se'. Es responsable de la realización de su 'nota personal' en la vida que lleva.

\section{Conclusión: la imposibilidad de una comunidad perfecta}

Edith Stein insiste en el hecho de que todo individuo humano se caracteriza esencialmente por su pertenencia a las tres formas sociales analizadas más arriba. La sociedad no aparece como una realidad independiente de la comunidad, sino que participa de la comunidad, al poner, por ejemplo, algunas de sus realidades entre paréntesis. ${ }^{50}$

${ }^{50}$ La comunidad es al mismo tiempo superior - desde el punto de vista personal y espiritual-, e 'inferior' a la sociedad: depende de una relación más ingenua y más simple entre las personas. Edith Stein precisa en su obra De l'Etat [Sobre el Estado] que "la particularidad de la sociedad reside en el hecho de que, en oposición con la comunidad, los individuos son ahí objetos los unos para los otros: sí, ciertamente; objetos y no sujetos que viven juntos en comunidad. Evidentemente hay que tomar esto cum grano salis, en la medida en que no se trata simplemente de objetos, sino de sujetos objetivados, donde esta objetivación presupone la simple relación con el sujeto, propio de la actitud comunitaria. Podemos entonces comprender a la sociedad como una variante racional de la comunidad. Lo que 'se da por sentado' en la coexistencia ingenua es en la vida social suscitado por actos deliberados". Edith Stein, Eine Untersuchung über den Staat, 1970, Tübingen, Max Niemeyer, p. 286. 
El individuo puede vivir más en una u otra de las formas sociales, dependiendo de que decida libremente vivir más cerca del centro de su alma espiritual que en la periferia de su ser. Edith Stein le otorga a la comunidad una condición ontológica superior a la de las otras dos formas sociales desde el punto de vista de la dimensión personal y espiritual del individuo y de su realización. Retoma la noción filosófica aristotélica del ser humano como un animal político que no está reducido a su función social, sino que se realiza por medio de sus acciones. Éstas realizan tanto al individuo como a la comunidad de la que forma parte. La realización personal va a la par con la realización de la comunidad de los sujetos pensantes y amantes. La reconciliación entre la sociedad y la comunidad puede tener lugar en la medida en que la 'función' del individuo es transformada en un servicio a la comunidad, comprendido como un don de sí. Allí donde el bien del individuo se reúne con el bien de la comunidad (e inversamente), la sociedad se transforma, como lo afirma Max Frisch, en una comunidad. Una comunidad así no se realiza, sin embargo, con el advenimiento de una sociedad sin clases, como lo propone Ernst Bloch, ni por un progreso técnico, sino por una conversión personal y fundamentalmente libre de los sujetos para vivir plenamente su 'nota personal'. Semejante perfeccionamiento de la comunidad gracias al amor entre los sujetos es, sin embargo, imposible de alcanzar en el marco de la temporalidad.

Frente a ella [la comunidad auténtica] se encuentra la imagen de una comunidad realizada que no puede ser alcanzada por ninguna comunidad terrestre -y no solamente de manera accidental, sino por principio- $[\ldots]$ Toda comunidad terrestre está así impregnada de una imperfección intrínseca y de una tensión por superarse. ${ }^{51}$

${ }^{51}$ Edith Stein, "Individuum und Gemeinschaft", p. 258: "Vor ihr steht das Bild einer vollkommenen Gemeinschaft, das durch keine irdische Gemeinschaft erreicht werden kann -und zwar nicht zufällig, sondern prinzipiell nicht- (...) Jeder irdischen Gemeinschaft haftet somit eine innere Unvollkommenheit an und ein Streben über sich selbst hinaus." 
Toda comunidad, incluyendo la que está formada por la pareja o los amigos, tiene que superarse. En efecto, el amor humano no alcanza una cima: los actos de amor y de amistad siempre son perfectibles. La persona puede constantemente darse y amar más, y por ello puede contribuir incansablemente a la perfección de su comunidad. 
La reproducción total o parcial de este artículo se podrá hacer si el ITAM otorga la autorización previamente por escrito. 